\title{
НЕКОТОРЫЕ АСПЕКТЫ МАЛОГО БИЗНЕСА И ЧАСТНОГО ПРЕДПРИНИМАТЕЛЬСТВА В УЗБЕКИСТАНЕ
}

\author{
Файзулла Талипов, к.и.н. дочент., \\ научный соискатель Национального \\ университета Узбекистана (Ташкент) \\ DOI: https://doi.org/10.31435/rsglobal_ijite/31032019/6378
}

\author{
ARTICLE INFO \\ Received 25 January 2019 \\ Accepted 19 March 2019 \\ Published 31 March 2019

\section{KEYWORDS} \\ small business, \\ entrepreneurship, farming, \\ field services, property, \\ community, small business, \\ privatization, problems, \\ employment.
}

\begin{abstract}
The article discusses issues of support of small business and entrepreneurship in Uzbekistan as well as service industries and their improvement. It traces the achievements and problems, and their solutions.
\end{abstract}

Citation: Файзулла Талипов. (2019) Some of the Features of Small Business and Entrepreneurship in Uzbekistan. International Journal of Innovative Technologies in Economy.2(22). doi: 10.31435/rsglobal_ijite/31032019/6378

Copyright: (C) 2019 Файзулла Талипов. This is an open-access article distributed under the terms of the Creative Commons Attribution License (CC BY). The use, distribution or reproduction in other forums is permitted, provided the original author(s) or licensor are credited and that the original publication in this journal is cited, in accordance with accepted academic practice. No use, distribution or reproduction is permitted which does not comply with these terms.

На сегодняшний день в Узбекистане малый бизнес и частное предпринимательство во всех сферах содействует развитию и формированию собственников по нормализации экономической ситуации в стране. Бизнес - это приносящая доход деятельность, которая служит для обогащения рынка основными потребительскими товарами и услугами. Эта система направлена на создание новых рабочих мест и увеличение доходов населения. Принятые Указы Президента Республики Узбекистан «О мерах по дальнейшему углублению экономических реформ, защите частной собственности и развитию предпринимательства» (1994 г.), «Об инициировании и стимулировании частного предпринимательства», (1995 г.) привели к децентрализации государственного имущества формированию класса собственников [1].

Число людей, занятых в этой области, увеличивается с каждым годом, что способствует развитию предпринимательства в стране. В 2007-2011 годах численность занятых на лицензированных предприятиях, не имеющих правового статуса, с 140,8 тыс. человек увеличилась до 698,4 тыс. то и есть вырос в 4,96 раз. Численность населения, занятого в дехканских хозяйствах, увеличилась с 1472,5 тыс. человек до 1745 тыс., т. е. рост составляет более $18,5 \%$ [2, с.95-97]. Это свидетельствует, что в стране развивается семейный бизнес, предпринимательство и ремесленничество.

Благодаря вниманию государства по поддержке малого бизнеса и частного предпринимательства его доля в ВВП страны с каждым годом растет. В частности, в 2000 году около 31 процента валового внутреннего продукта приходилось на этот сектор экономики, в 2008 году он составлял 48,2 процента, в 2009 году - 50,1 процента, в 2010 году - 52,5 процентов, в 2011 году - 54 процента или по сравнению с 2000 годом увеличился на 23 процента. К 2015 году более 74 процентов работающего населения занято в сфере малого бизнеса и частного 
предпринимательства. С увеличением кредитования коммерческими банками усиливается внимание к этой области, в том числе, создание новых рабочих мест и формирование устойчивых источников дохода.

В последние годы наблюдаются положительные тенденции в структуре занятости населения. Например, в начале 1990-х годов в результате создания благоприятных условий для ведения бизнеса численность занятых работников в сельскохозяйственном секторе составляла 40 процентов, в последние годы этот показатель значительно снизился. Например, к 2000 году этот показатель упал до 25 процентов. Количество сотрудников, занятых в сфере услуг, транспорта и строительства увеличилось с $36 \%$ до 52\%. За последние пять лет было создано всего 3,8 млн. новых рабочих мест в результате реализации программ занятости, поддержки и развития предпринимательства во всех секторах экономики. Более $74 \%$ из них относятся к сфере малого бизнеса и частного предпринимательства. В целях создания новых рабочих мест и увеличения занятости населения к 2016 году коммерческие банки выделили кредиты на сумму более 1 трлн. сумов для малого бизнеса и частного предпринимательства [3, стр. 38-39].

С развитием числа сферы услуг и обслуживания, в частности малых предприятий, в 2011 году количество занятого сельского населения значительно сократилась. Так, по всей республике количество рабочих мест, созданных с помощью предпринимательства в течение 2010-2016 гг. увеличилось на 3,9\%. В 2017 году был создан проект занятости населения и, согласно программе, усилена деятельность областных, районных и городских властей по развитию промышленности (с 5440 до 131 тыс. рабочих мест по проекту), сельского хозяйства (с 8430 до 55,8 тыс. рабочих мест по проекту) и сферы услуг (с 11 тыс. до 69,5 тыс. по проекту). В дальнейшем в стране за счет реализации почти 25 тыс. инвестиционных проектов предоставляется создание 256,4 тысяч рабочих мест [4, с. 167].

Однако в этих областях существует ряд проблем, и одной из самых больших проблем является недостаточное вовлечение молодежи в малый бизнес и предпринимательство. Узбекистан является быстро растущей страной рабочей силы. Особенность страны заключается в том, что численность рабочей силы в стране растет в среднем на уровне $2,2 \%$ за год [3, с. 3839]. Такая ситуация при трудоустройстве на местах может вызвать серьезные проблемы. Также имели незаконные проверки деятельности предпринимательских работ, и эти проблемы существовали в течение многих лет.

С июля по декабрь 2017 года в городах и селах республики были организованы «Сайёр кабуллар (Виртуальные приемные)» с целью ведения активного диалога с народом, инициированного Президентом Республики, для дальнейшего совершенствования системы работы с обращениями физических и юридических лиц. В открытых диалогах более 58000 граждан и предпринимателей рассмотрены 32176 жалоб, заявлений и предложений по различным вопросам. Примечательно, что максимальное количество жалоб, или более 8000 , или 25\%, в основном связано с проблемами предпринимателей с предоставлением банковских кредитов. Из них проблемы правоохранительных органов составляют более 7 тыс. - 22\%, занятость и заработная плата - 3 тыс.973-12\%, проблемы, стоящие перед предпринимательством - 3 тыс. 350 - 10\%, выделение земли и жилья населению составляет - 2 тыс. $473-8 \%$ и др. До настоящего времени было совершенно решено 30 тыс. 876 контактов, что составляет 96\% от всех обращений. Из них, 8326 предложений рекомендовано и отправлено для решения по отраслям промышленности [5, № 15].

Тем не менее, в Республике 5 тыс. 771 малообеспеченной семье, желающим получить кредит было выдано 33,3 млрд. сумов льготных кредитов из сфер финансов, агентств занятости, профсоюзов, банков и других ответственных государственных учреждений. В результате регистрации во всех регионах страны было выявлено 1832 пустых здания и сооружения, а за счет целевых средств предпринимателей и банковских кредитов было разработано 1485 проектов на сумму 734 млрд. сумов. В настоящее время 415 из числа этих проектов были одобрены местными властями. Общая стоимость этих проектов составляет 95,8 млрд. сумов, из которых 63,7 млрд. сумов за счет собственных средств инициаторов по реализации проектов.

По инициативе Президента Шавката Мирзиёева 2018 год был объявлен «Годом поддержки активного предпринимательства, инновационных идей и технологий» в связи с этим аудиторская проверка финансово-хозяйственной деятельности всех хозяйствующих субъектов приостановлена на 2 года. В частности, объективное и своевременное рассмотрения 
обращений, поступивших в «Народные приемные» и «Виртуальную приемную», при Президента Республики Узбекистан, является важнейшим элементом системы и на практике оправдывает себя как демократическая система обращений граждан.

Например, с конца 2017 года по первую половину 2018 года более 1,5 миллиона человек обратились к «Народные приемные», из них сотни тысяч нерешенных вопросов были положительно решены за эти годы. Это говорит о том, что в современном, модернизированном Узбекистане система народной власти существует и фактическим реализуется во имя народа. По состоянию на 1 апреля 2017 года объем кредитов, выделенных малому бизнесу и частному предпринимательству в стране, составил 4,6 трлн. сумов, это в 1,3 раза больше, чем за аналогичный период 2016 года. 1 трлн. сумов состоит из микрокредитов, что в 1,3 раза больше, чем за аналогичный периода [6: Отчёт благотворительного фонда «Махалля»]. В то же время в местных органах власти созданы целевые фонды «Благоустроенное село», которые также поддерживают малый бизнес и частное предпринимательство.

В итоге можно сказать, что сегодня основная задача в Узбекистане создать благоприятную удобную сферу бизнеса и услуг, для развития малого бизнеса, в том числе частного предпринимательства. В предпринимательстве создаются различные выгоды, чем пользуются также и нуждающиеся слои населения. Можно полагать, что при помощи и поддержке этих секторов страна вступит в следующую стадию развития.

\section{ЛИТЕРАТУРА}

1. https://nrm.uz. «O мерах по дальнейшему углублению экономических реформ, обеспечению защиты частной собственности и развитию предпринимательства»/УП РУз. от 21.01.1994 г. N УП-745.; «Об инициировании и стимулировании частного предпринимательства»/УП РУз. от 05.01.1995 г. N УП-1030

2. Основные тенденции и показатели экономического и социального развития Республики Узбекистан за годы независимости (1990-2010) и прогноз на 2011-2015 годы. Стат. Сб. - Ташкент: Узбекистан, 2011.

3. http://gazeta.uz. Махалля - центр развития частного предпринимательства и семейного бизнеса. Газета «Махалля». - Ташкент: 2015.

4. Научно-методическая брошюра «Год диалога с народом и интересов человека» в 2017 г. по изучению государственной программы по реализации «Стратегия действий» по пяти приоритетным направлениям развития Республики Узбекистан на 2017-2021 годы. - Ташкент: Узбекистан, 2017.

5. (Виртуальные приемы: итоги и выводы) // Газета «Хукук». 12 апреля 2018 г. № 15

6. Действующий архив благотворительного фонда «Махалля» Республики Узбекистан. 